\title{
Rodez « Segodunum »
}

3, impasse Cambon

\section{(2) OpenEdition}

Journals

Édition électronique

URL : http://journals.openedition.org/adlfi/11042

ISSN : 2114-0502

Éditeur

Ministère de la culture

\section{Référence électronique}

"Rodez «Segodunum » , ADLFI. Archéologie de la France - Informations [En ligne], Midi-Pyrénées, mis en ligne le 01 mars 1997, consulté le 20 avril 2019. URL : http://journals.openedition.org/adlfi/11042

Ce document a été généré automatiquement le 20 avril 2019

(c) Ministère de la Culture et de la Communication, CNRS 


\title{
Rodez « Segodunum »
}

\section{3, impasse Cambon}

\author{
Date de l'opération : 1990 (DF) \\ Inventeur(s) : Dausse Lucien
}

1 Des travaux de reprises en sous-œuvre ont nécessité la surveillance de terrassements dans un secteur archéologiquement sensible (Gallia Informations, 1989 : 86-87) [ (Fig. n¹ : Plan général), plan général, site g].

2 Deux murs parallèles parementés distants de $3 \mathrm{~m}$, orientés nord-est-sud-est et larges de $0,50 \mathrm{~m}$ pour une hauteur conservée de $0,40 \mathrm{~m}$, délimitent une pièce au sol pavé de grandes dalles degrés disposés en opus incertum. Cette partie de bâtiment dont la destination reste imprécise paraît avoir été en fonction $\mathrm{du} \mathrm{I}^{\mathrm{er}} \mathrm{s}$. au $\mathrm{II}^{\mathrm{e}} \mathrm{s}$. de notre ère (sigillées sud-gauloises, Drag. 29, 30, 24/25, Herm. 33, amphores Dr. 20 et 28, cruches peintes en blanc, etc.). Les terres de remblais immédiatement supérieures aux niveaux d'abandon ont livré, outre des céramiques du Bas-Empire, un échantillonnage céramique couvrant les périodes médiévales et modernes.

\section{ANNEXES}


Fig. $n^{\circ} 1$ : Plan général

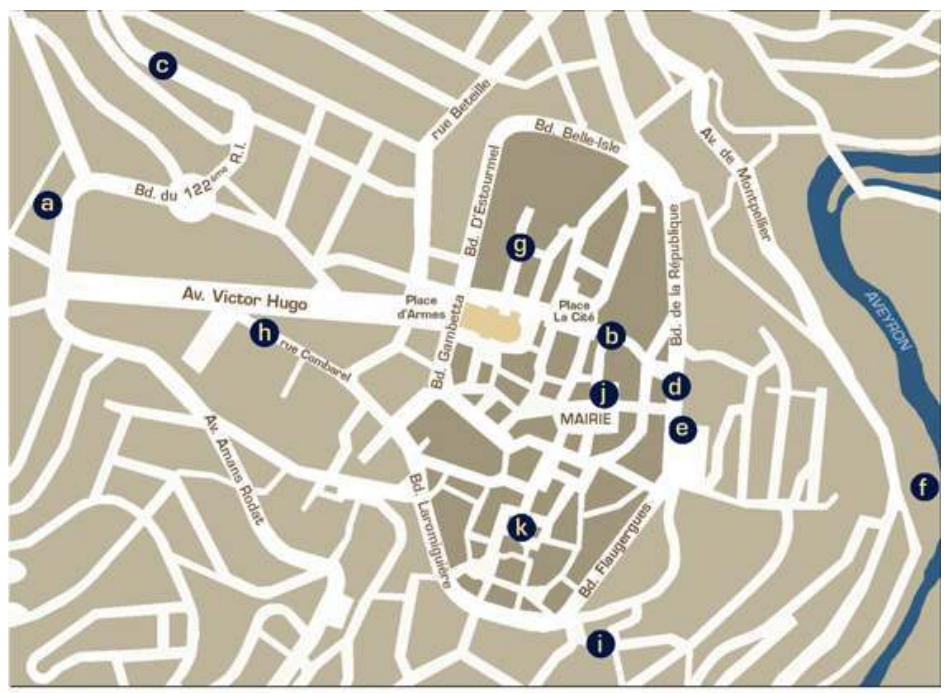

Plan général : RoDez

Localisation des fouilles effectuées dans la ville

a) Caserne Rauch

b) rue Aristide-Briand

c) boulevard du $122^{\mathrm{e}}$ régiment

d'Infanterie

d) 22 , boulevard Denys-Puech

e) place Clémenceau

f) Les Attizals

g) 3, impasse Cambon h) 25 , rue Combarel

i) La Tour de la Boule d'Or, boulevard

Flaugergues

j) Les Jacobins, Raynaldi-J aurès

k) autour de l'église Saint-Aman

(rue Villaret, place des Toiles,

rue Cassagnes, rue de la Madeleine,

rue Lebon)

GI 1997 ; CNRS Éditions 1998 (1997)

\section{INDEX}

Index chronologique : Antiquité romaine, ép médiévale, Temps Modernes Index géographique : Midi-Pyrénées, Aveyron, Rodez

operation découverte fortuite (DF) 